\section{State of the art in vivo imaging techniques for laboratory animals}

\author{
David Tibor Lauber ${ }^{1}$, András Fülöp ${ }^{1}$, Tibor Kovács ${ }^{1,2}$, \\ Krisztián Szigeti ${ }^{2}$, Domokos Máthé ${ }^{2,3, *}$ and Attila Szijártó ${ }^{1, *}$
}

Laboratory Animals

0(0) 1-14

(C) The Author(s) 2017

Reprints and permissions: sagepub.co.uk/

journalsPermissions.nav

DOI: $10.1177 / 0023677217695852$

journals.sagepub.com/home/lan

@SAGE

\begin{abstract}
In recent decades, imaging devices have become indispensable tools in the basic sciences, in preclinical research and in modern drug development. The rapidly evolving high-resolution in vivo imaging technologies provide a unique opportunity for studying biological processes of living organisms in real time on a molecular level. State of the art small-animal imaging modalities provide non-invasive images rich in quantitative anatomical and functional information, which renders longitudinal studies possible allowing precise monitoring of disease progression and response to therapy in models of different diseases. The number of animals in a scientific investigation can be substantially reduced using imaging techniques, which is in full compliance with the ethical endeavours for the 3R (reduction, refinement, replacement) policies formulated by Russell and Burch; furthermore, biological variability can be alleviated, as each animal serves as its own control. The most suitable and commonly used imaging modalities for in vivo small-animal imaging are optical imaging (OI), ultrasonography (US), computed tomography (CT), magnetic resonance imaging (MRI), and finally the methods of nuclear medicine: positron emission tomography (PET) and single photon emission computed tomography (SPECT).
\end{abstract}

\title{
Keywords
}

imaging modalities, MRI, CT, optical imaging, molecular imaging

Date received: 13 December 2016; accepted: 6 February 2017

\section{Preclinical imaging}

Prior to the concept of 'small-animal imaging', experimental animals could only be imaged using clinical instrumentation. ${ }^{1}$ However, preclinical research mostly utilizes rodent models (mice or rats), which in many instances are too small to be imaged accurately by clinical imaging devices. Low spatial resolution, low sensitivity and poor tissue contrast proved to be most limiting. Overcoming these limitations and improving overall imaging performance was achieved by introducing specific refinements and alterations to instrumentation. ${ }^{1}$ Despite these adjustments, imaging small laboratory animals remains a major challenge. The size of the imaged subjects, the total volume to be evaluated, the spatial resolution necessary to detect anatomical or functional changes and the total time that may be dedicated to acquiring an image are fundamentally different for a $20-30 \mathrm{~g}$ mouse than for a $70 \mathrm{~kg}$ human. ${ }^{2}$ The primary challenge is to obtain the highest possible signal-to-noise ratio (SNR), and to localize the signal as accurately as possible with good temporal resolution with a minimal amount of molecular probe. ${ }^{3}$

The most appropriate of the available imaging modalities for in vivo small-animal imaging are optical imaging (OI), ultrasonography (US), computed tomography (CT), magnetic resonance imaging (MRI) and, last but not least, the methods of nuclear medicine: positron emission tomography (PET) and single

\footnotetext{
${ }^{1}$ Hepato-Pancreatico-Biliary Surgery Research Center Hungary, 1st Department of Surgery, Semmelweis University, Budapest, Hungary

${ }^{2}$ Department of Biophysics and Radiation Biology, Semmelweis University, Budapest, Hungary

${ }^{3}$ CROmed Translational Research Centers Ltd, Budapest, Hungary

*Attila Szijártó and Domokos Máthé are joint senior authors.
}

Corresponding author:

Krisztián Szigeti, PhD, Department of Biophysics and Radiation Biology, Semmelweis University, Túzoltó str. 37-43, H-1094 Budapest, Hungary.

Email: szigeti.krisztianamed.semmelweis-univ.hu 
photon emission computed tomography (SPECT). ${ }^{4}$ The most important distinguishing parameters are the form of applied radiation of image generation (ionizing or non-ionizing), temporal and spatial resolutions, penetration depth, availability of injectable or biocompatible molecular probes or contrast agents and the respective detection threshold of the probes ${ }^{3,5}$ (Table 1).

\section{Micro-CT}

Computed tomography and MRI provide detailed anatomical cross-sectional images. These two groundbreaking technologies have virtually transformed modern healthcare services. In recognition of their importance the Nobel Prize was jointly awarded to Allan M Cormack and Godfrey N Hounsfield for the invention of CT in 1979 and to Paul C Lauterbur and Sir Peter Mansfield for the invention of MRI in 2003. The evolution of electronics and engineering led to the development of miniaturized versions of CT (micro$\mathrm{CT}$ ) and MRI (micro-MRI), which are now commercially available and are optimized for small-animal imaging in preclinical research. ${ }^{6}$

Computed tomography calculates the attenuation of $\mathrm{X}$-ray for single tissue volume elements (voxels) and creates three dimensional (3D) matrix images, from which sectional or spatial images can be reconstructed. A typical CT device consists of an X-ray tube and a 2D $\mathrm{X}$-ray detector assembled in opposing positions in a gantry, which rotates around the examined object. Some preclinical systems, mainly used for imaging ex vivo specimens, have a static radiation source and an $\mathrm{X}$-ray detector, while the examined object rotates within the circular apparatus. ${ }^{7,8} \mathrm{X}$-ray attenuation mainly depends on tissue density and the atomic number of the elements contained in the voxels. Therefore, tissues with higher atomic numbers and higher densities, such as bone $\left(Z_{(\mathrm{Ca})}=20\right)$, yield excellent images with sharp contrast. On the other hand, soft tissues associated with lower atomic numbers and lower densities have very poor contrast, and are therefore often required to be accentuated by using certain contrast agents $\left(\mathrm{Z}_{(\mathrm{I})}=53, \mathrm{Z}_{(\mathrm{Br})}=35\right)$.

The components of micro-CT devices have been finetuned to achieve maximal spatial resolution and to optimize SNR: the properties of the X-ray tubes were modified, as were pixel pitch and matrix size of the detectors, the source detector distance and size of the focal spot. ${ }^{9}$ In contrast to a minimum focal spot size of $300 \mu \mathrm{m}$ in conventional clinical CT systems, focal spot size could be downscaled to $1-10 \mu \mathrm{m}$ in micro-focus CT scanners which significantly diminished penumbra blurring and led to images with much sharper contours. ${ }^{9,10}$ Due to these technical innovations micro-CT provides tomographic data at microscopic spatial resolution $(10-200 \mu \mathrm{m})$ and a temporal resolution in a minute timescale. $^{11}$

Micro-CT is ideal for imaging osseous structures or the lung, due to distinct differences in density, and it is also well suited for imaging cardiac function and tumour growth. ${ }^{12}$ Despite the sharp air-to-tissue contrast, preclinical imaging of the lung is cumbersome because of the minuscule size and rapid physiological movement of the structures in question (the mean respiratory rate of a laboratory rat is $85 / \mathrm{min}) .{ }^{11}$ The introduction of cardiorespiratory gating systems in recent years has led to substantial improvements in image quality and contrast. ${ }^{13,14}$

However, similar densities make soft tissue differentiation with CT difficult. The use of contrast agents increases sensitivity by highlighting the vascular system, specific organs or tissues. For a long time, conventional water soluble intravenous iodide-based contrast agents were not applicable in rodents, due to the much smaller voxel size and much faster circulation, ${ }^{15}$ which diminish the contrast medium in seconds. ${ }^{16}$ Since then, faster X-ray detectors have been developed with readouts of between 30 and 60 frames per second (fps), which allows for intravenous bolus imaging. ${ }^{17}$ Bloodpool contrast agents have a longer half-life, either because they are macromolecules with lower elimination rate or they are bound to plasma proteins. These contrast agents allow experimental setups with longer scan times; however, the level of contrast is generally lower than with conventional contrast agents. ${ }^{17,18}$ Newer liposome-based blood-pool contrast agents containing high concentrations of iodine or metal nanoparticles (e.g. gold $[\mathrm{Au}]$ or barium [Ba]) have a longer half-life, while offering improved detail perceptibility particularly in small anatomical structures. ${ }^{19-22}$

The main advantages of micro-CT are high spatial resolution, detailed morphological information and relatively short scanning times (10-15 min). Nevertheless, the volume of contrast agents used to enhance the contrast resolution of soft tissue becomes a potential limitation, particularly when imaging a series. Furthermore, a longitudinal experimental setup requires balancing image contrast and resolution with the radiation burden associated with $\mathrm{CT}$ imaging. ${ }^{23}$ Although radiation levels used in micro-CT are not lethal to animals, the levels may still surpass the threshold associated with changes in immune response and other biological pathways that may alter experimental outcomes. $^{24}$

\section{Micro-MRI}

Three-dimensional imaging based on MR might be recognized as the most innovative, versatile and useful 


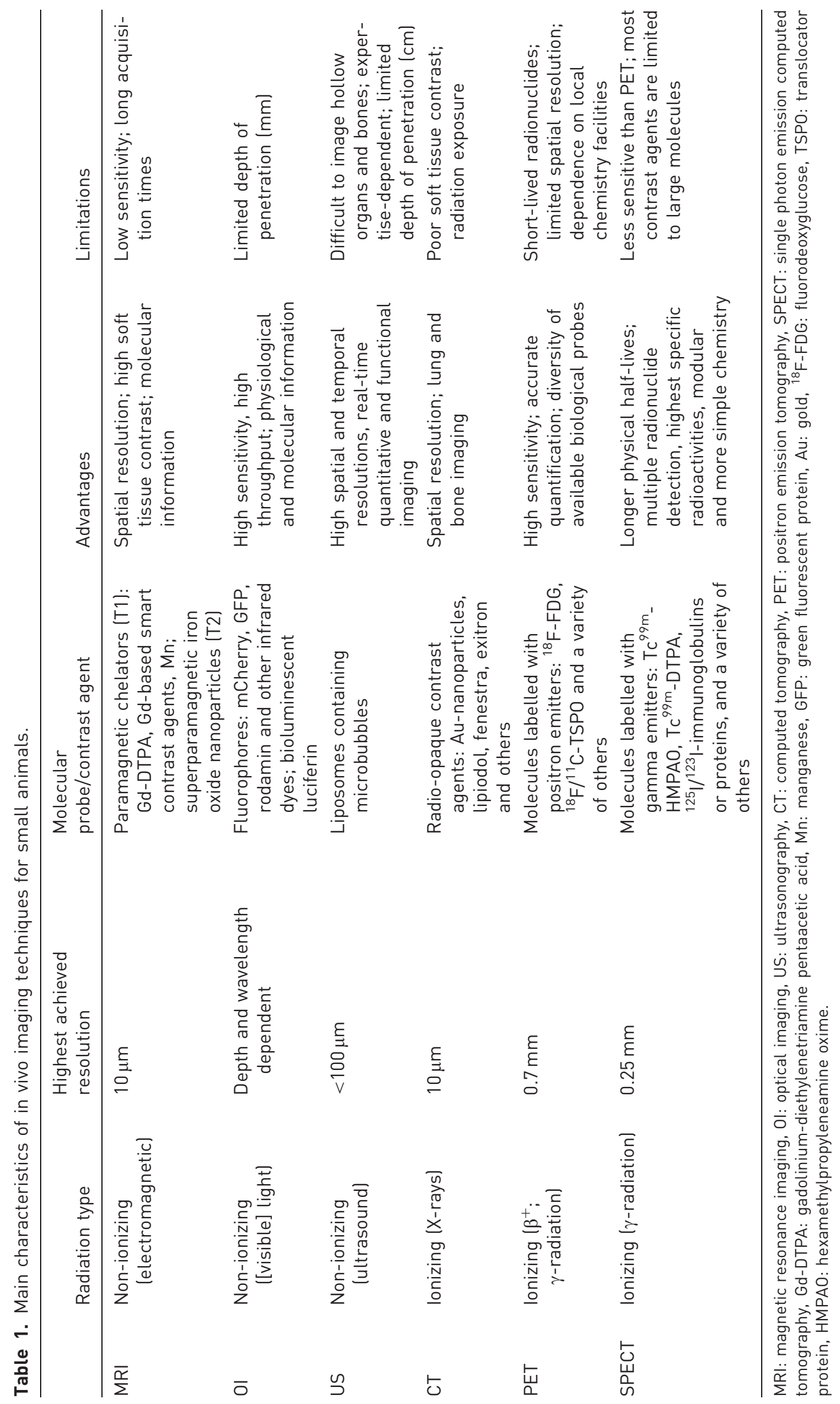


application of quantum physics in medicine. MRI is capable of whole-body in vivo imaging, producing high-contrast images of soft tissue without the need for ionizing radiation. Clinical 1.5-3.0 T MRI scanners could also be used for targeted imaging in mediumsized animals such as rabbits, albeit with limited spatial resolution. ${ }^{25}$ However, modern micro-MRI devices are suited for high-resolution (below $100 \mu \mathrm{m}$ ) imaging of small-bodied rodents with excellent contrast for soft tissue differentiation. ${ }^{26}$

Magnetic resonance imaging is based on the interaction of nuclear spin (a quantum-physical property) and an external magnetic field. The dominant nuclear particle in MRI is the proton in hydrogen $\left({ }^{1} \mathrm{H}\right)$, the spin of which is in precession about the magnetic field direction. Atomic spin can be manipulated with a combination of magnetic fields resulting from radiofrequency (RF) impulses. Imaging rests on the ability to detect the bulk precession of the hydrogen spins in water, fat and other organic molecules, and to determine the time for spin magnetization to rebuild along the direction of the static magnetic field (T1 relaxation) or the time until dephasing of clusters of spins (T2 relaxation). ${ }^{27}$ Signal strength correlates with proton density, and signal pattern is influenced by the microenvironment of the protons in individual tissues. ${ }^{28,29}$ To produce images with much finer resolution, micro-MRI uses stronger magnets, specific receiver coils and RF receiver chains as well as stronger gradient sets compared with clinical instrumentation. Visualizing fine tissue anatomy details or blood flow changes with good MR resolution requires high SNR. For these applications MR systems operating at or over $7 \mathrm{~T}$ field strengths are optimal. For many molecular imaging applications such as chemical exchange saturation transfer (CEST), even with $1 \mathrm{~T}$ or $3 \mathrm{~T}$ translational field strength, smallanimal systems offer the appropriate performance. ${ }^{23}$ Typical MRI contrast agents are paramagnetic chelators (i.e. gadolinium - T1, manganese - T2 and superparamagnetic iron oxide [SPIO] - T2), which lead to higher target tissue contrast by altering the magnetic micro-environment. ${ }^{26}$

Furthermore, minor modification of the measuring technique and analysis of data by the introduction of special algorithms enables MRI to provide valuable and unique information on biological processes via, for example:

(1) The differentiation between oxyhaemoglobin and deoxyhaemoglobin based on their different magnetic properties (the former being diamagnetic, the latter paramagnetic). Functional MRI (fMRI) assesses blood oxygenation by determining the haemoglobin concentration of blood, fMRI is thus capable of indirectly revealing and highlighting activated brain structures via their higher oxygen transport by blood. ${ }^{30}$

(2) Imaging based on intravenous bolus injection of exogenous contrast agents is called dynamic contrast-enhanced imaging (DCE-MRI), which can also be used to determine vascular permeability with contrast molecules of varying sizes.

(3) Recently, non-invasive perfusion measurements have also become entirely possible: arterial spin labelling (ASL) for instance utilizes arterial blood water magnetization itself as an endogenous contrast agent. ${ }^{31}$

(4) Diffusion weighted imaging (DWI) shows the different properties of diffusion in tissues by detecting the motion of protons (mainly water), which is restricted by various intercellular structures resulting in certain diffusion patterns which reflect the conditions of tissue structure or cell density. This method is applied to detect neuronal pathways (tractography), for tumour differentiation or early recognition of cerebral ischaemia. ${ }^{23,32}$

(5) Magnetic resonance spectroscopy (MRS) provides information about tissue biochemistry by determining the concentration of different chemicals or metabolites. This technique mostly assesses molecules rich in hydrogen (choline, creatinine, lipids and amino acids ${ }^{33}$ ); nevertheless, chemicals composed of atoms (such as phosphorus $\left[{ }^{31} \mathrm{P}\right]$, carbon $\left[{ }^{13} \mathrm{C}\right]$, lithium $\left[{ }^{7} \mathrm{Li}\right]$, fluorine $\left[{ }^{19} \mathrm{~F}\right]$ or sodium $\left[{ }^{23} \mathrm{Na}\right]^{34}$ ) can also be detected by modifying the coils, generators and assessment sequences. MRS is mainly applied to examine brain metabolism, to differentiate tumorous tissues or to assess drug pharmacodynamics. ${ }^{33,35,36}$

(6) Hyperpolarized nuclear MRI relies on MR spectroscopic maps obtained from acquisitions yielding time-domain information. In particular, it is possible to monitor the biochemical transformations of specific substrates that are delivered to subjects. As this method provides data on the kinetics of the conversion of substrates into metabolites, MRS of the carbon nuclei $\left({ }^{13} \mathrm{C}\right)$ is one of the most powerful techniques of investigating intermediary metabolism. Specially prepared solutions of hyperpolarized ${ }^{13} \mathrm{C}$-containing substrates such as hyperpolarized ${ }^{13} \mathrm{C}$-pyruvate are usually applied both in animal models of cancer and clinical cancer patients for the in situ, in vivo detection of the Warburg effect by imaging the increase in endogenous lactate levels in tissues. Other hyperpolarized nuclear MRS methods using ${ }^{129} \mathrm{Xe}$ or ${ }^{3} \mathrm{He}$ noble gases have also found translational applications recently. ${ }^{37,38}$

Micro-MRI produces morphological images with high resolution and excellent tissue contrast. 
Furthermore, it provides information regarding tissue composition, perfusion, oxygenation, tissue elasticity, metabolism, and also enables detection of molecular probes; all within a single acquisition session without any radiation exposure. Thus, MRI is arguably the most versatile modality. ${ }^{39}$ Micro-MRI is an essential part of preclinical cardiovascular research, providing valuable information regarding tissue structure, function and perfusion, both on cellular and at molecular levels. ${ }^{13,40}$ In oncological research, micro-MRI is an excellent modality for monitoring tumour growth and development, tumour differentiation, perfusion imaging, oxygenation and angiogenesis, and particularly for monitoring tumour growth and degradation in response to therapy. ${ }^{25,35,41}$ Assessment of osseous structures remains a challenge because of the low water content $(15 \%)$ of bone volume, nevertheless, micro-MRI has also been successfully applied in the assessment of musculoskeletal tissue structures such as tendons, cartilage, menisci, and ligaments. ${ }^{28}$ The lower sensitivity of MRI molecular methods can be compensated for by the application of complementary or hybrid methods (e.g. SPECT or PET, see below). ${ }^{39,42}$

\section{Nuclear medicine or molecular imaging}

Imaging in nuclear medicine rests on two core principles: (1) A variety of biomolecules can be labelled with radioactive isotopes which are referred to as radiopharmaceuticals or radioactive tracer molecules. (2) Radiotracers tend to accumulate in certain localizations due to physiological processes (such as active or passive transport mechanisms, metabolism, phagocytosis and microembolization) according to the principle of the dynamic state of body constituents. Therefore, metabolic processes can be quantified topographically measuring tracer concentrations within anatomical structures (standardized uptake value [SUV]) as well as temporally assessing the time course of tracer concentrations (Logan et al. ${ }^{43}$ or Gjedde ${ }^{44}$ and Patlak ${ }^{45}$ plots). Thus, biochemical and physiological processes become detectable and traceable in real time from cellular and molecular levels up to organ or organism levels without interfering with normal physiology. ${ }^{46}$ The modalities of nuclear imaging are 'planar scintigraphy' yielding a $2 \mathrm{D}$ image, SPECT, which is the $3 \mathrm{D}$ version of the former, and PET. The downscaled models of each (micro-SPECT, micro-PET) are well established modalities of preclinical research.

Micro-SPECT and planar scintigraphy. Micro-SPECT and planar scintigraphy are based on the detection of $\gamma$ photons originating from the decay of atomic nuclei (radionuclides, mainly: ${ }^{99 \mathrm{~m}} \mathrm{Tc},{ }^{67} \mathrm{Ga},{ }^{201} \mathrm{Tl},{ }^{111} \mathrm{In}$ or $\left.{ }^{123},{ }^{125},{ }^{131} \mathrm{I}\right) .{ }^{47},{ }^{48}$ The gamma-camera consists of a detector crystal and a collimator, which is made of lead or tungsten and manufactured with multiple elongated holes, which are positioned in such a way that only photons which are travelling in a parallel orientation to the camera face can interact with the crystal. Conventional planar scintigraphy allows for the acquisition of the 2D projection of tracer distribution. ${ }^{49} \mathrm{In}$ SPECT imaging, the gamma-camera rotates around (or completely surrounds) the object and a number of projections at different angles are merged to produce $3 \mathrm{D}$ tomographic images. ${ }^{50,51}$

Preclinical SPECT systems apply pinhole collimation to obtain better spatial resolution by pinhole magnification. The use of multiple pinholes or other multiple collimation aperture formats also enhances imaging sensitivity. ${ }^{52}$ To further increase resolution and sensitivity, different crystal materials to the most widespread scintillation detector crystal $\mathrm{NaI}[\mathrm{Tl}]$ (e.g. $[\mathrm{CsI}(\mathrm{Tl})]$, $[\mathrm{CsI}(\mathrm{Na})]$ or $\left.\left[\mathrm{LaBr}_{3}(\mathrm{Ce})\right]\right)$ have been introduced. ${ }^{53}$ Modern systems are able to detect minute $\left(<10^{-10}\right.$ molar $)$ tracer concentrations $(0.1$ nanomol $)$ with submillimetre resolution $(0.5-0.7 \mathrm{~mm})$ in vivo. ${ }^{54,55}$ Some preclinical SPECT systems incorporate semiconductor detector materials $(\mathrm{CdTe}$ or $\mathrm{CdZnTe}$ [CZT]) offering the possibility of higher energy discrimination efficiency, which are important for low-energy radionuclides $\left({ }^{125} \mathrm{I}\right)$ and dual isotope applications. ${ }^{53,56}$ Gamma-photon-emitting isotopes eligible for SPECT imaging are usually elements with higher atomic numbers, which are suitable for labelling several molecules: from simple organic chelates to proteins, antibodies, hormones or selectins. However, diffusion and clearance of the resulting larger-molecule radiopharmaceuticals require a relatively long time due to the larger size of these molecules; thus radionuclides with a relatively longer half-life (hours) are to be used. ${ }^{54}$ Micro-SPECT is widely used in key areas of preclinical research: it is a well-established modality for cardiovascular research (e.g. to monitor myocardial function, perfusion, necrosis or angiogenesis ${ }^{40,57,58}$ ), stem-cell research, ${ }^{59,60}$ oncology (e.g. detection of in vivo gene expression and metastases, or molecular pathways of tumour formation $^{61,62}$ ), neurological research (e.g. research in Parkinson's and Alzheimer's diseases $\left.{ }^{63,64}\right)$ as well as for the development of new drugs ${ }^{26,65}$ (Figure 1).

Micro-PET. Positron emission tomography is also based on the detection of $\gamma$-photons. However, the tracers emit positrons (unstable subatomic $\mathrm{e}^{+}$-particles), which travel until they collide with an electron, their respective antiparticle. The distance travelled ('positron range') depends on the kinetic energy of the emitted positron (usually a few millimetres). The collision of a positron and an electron results in a process called annihilation: the annihilated particles are replaced by 


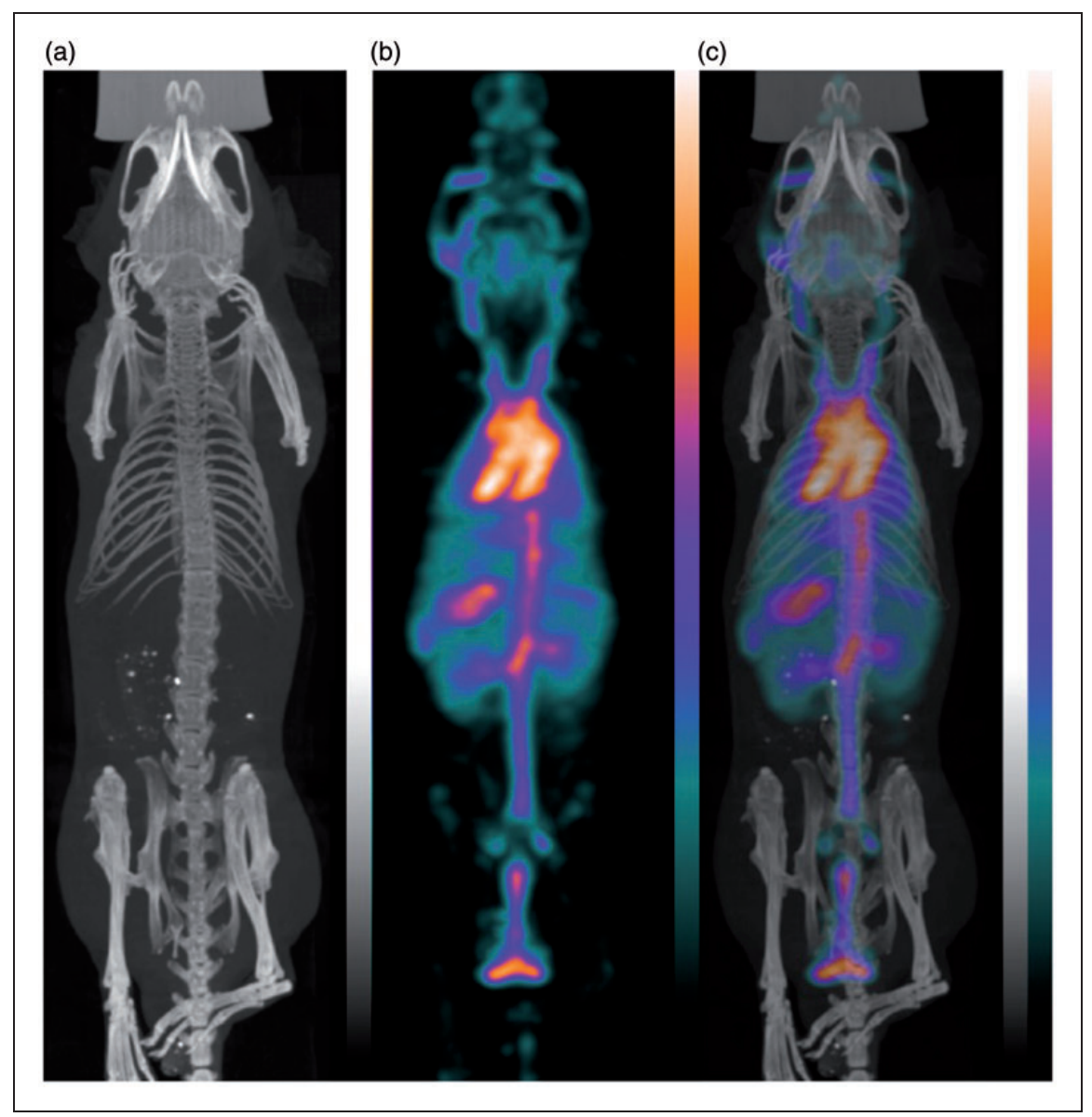

Figure 1. In vivo single photon emission computed tomography/computed tomography (SPECT/CT) imaging with radiolabelled human serum albumin. Radiolabelled human serum albumin ( ${ }^{125} \mathrm{I}$-HSA) was administered directly before SPECT/CT imaging. Osseous structures are clearly visible in the single modality CT images (a). SPECT images show distribution of ${ }^{125} \mathrm{I}$-HSA (b). The SPECT/CT fusion image allows exact anatomical localization of higher HSA concentration and identification of structures, e.g. carotid arteries, heart, aorta, liver, kidneys and urinary bladder (c). NanoSPECT/CT PLUS (Mediso, Budapest, Hungary). See Szigeti K, Horváth I, Veres DS, et al. A novel SPECT-based approach reveals early mechanisms of central and peripheral inflammation after cerebral ischemia.

J Cereb Blood Flow Metab 2015; 35: 1921-1929.

two $\gamma$-photons of fixed energy $(=511 \mathrm{keV})$, which travel along the same line but in opposite directions (at a $180^{\circ}$ angle). ${ }^{66}$ Therefore, a PET system must contain a pair of opposing detectors at a minimum, but the best overall sensitivity can be achieved by a full ring of detectors. Since photons travel at the speed of light, the opposing detectors will receive a signal almost simultaneously. ${ }^{67}$ Thus, the line determined by two photons which are detected within a short time window (usually 4-20 ns) determines the trajectory of the annihilation point, which is referred to as an electronic collimation. The absence of a physical collimator significantly improves the sensitivity of PET, which can be up to 100 times greater than SPECT, especially when 3D data are obtained. ${ }^{66}$ However, improving spatial resolution above a certain threshold is physically impossible (in contrast to SPECT) due to the methodical background of a positron range. ${ }^{68}$ Modern preclinical micro-PET systems achieve spatial resolution values of around $1.0 \mathrm{~mm}$ under optimal conditions (resolution of clinical systems is $6-10 \mathrm{~mm})^{68}$ partially owing to multiple advancements such replacing old bismuth germanate (BGO) scintillators by improved detector blocks made of inorganic scintillators, for example lutetium oxyorthosilicate (LSO), lutetium-yttrium oxyorthosilicate (LYSO) or gadolinium oxyorthosilicate (GSO) ${ }^{69,70}$ New compact silicate detectors, based on semiconductor technology, facilitate synchronous PET and MRI signal acquisitions, thus significantly reducing SNR and examination time. ${ }^{71,72}$

The most commonly used positron emitters are ${ }^{11} \mathrm{C}$ (carbon), ${ }^{13} \mathrm{~N}$ (nitrogen), ${ }^{15} \mathrm{O}$ (oxygen) and ${ }^{18} \mathrm{~F}$ (fluorine). The biggest advantage of carbon, nitrogen or oxygen isotopes is the possibility of labelling nearly 


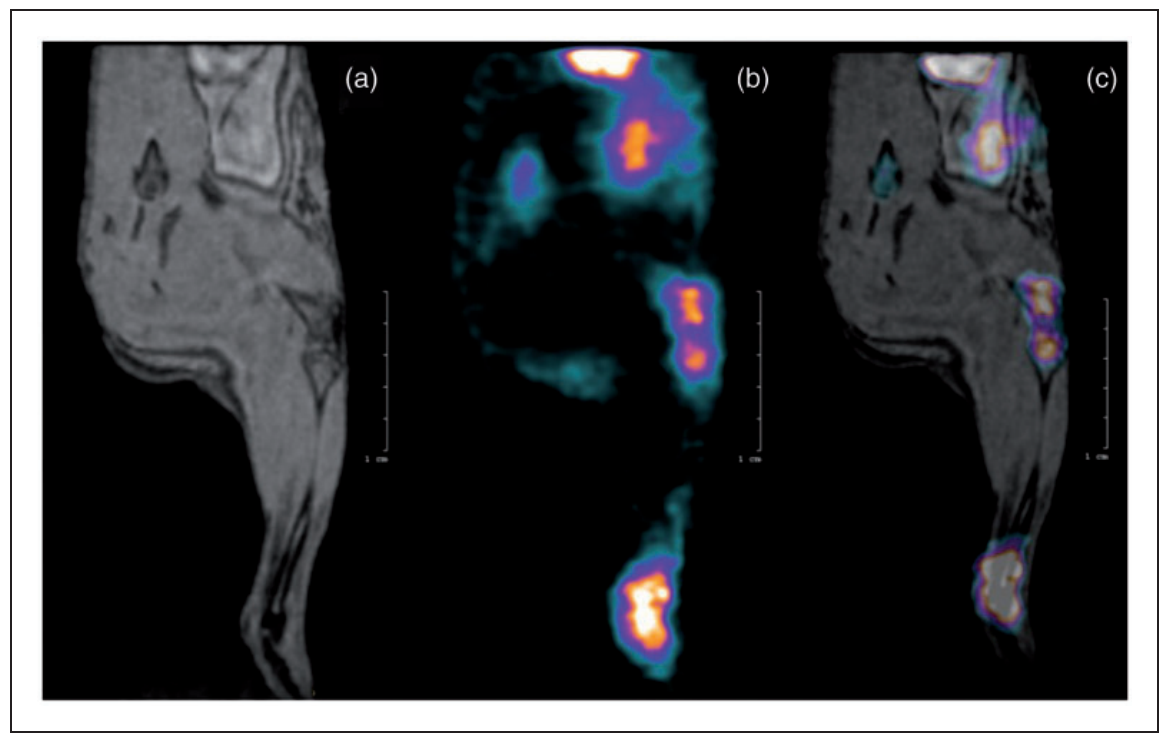

Figure 2. In vivo investigation of metabolic activity by fusion positron emission tomography/magnetic resonance imaging (PET/MRI). The first two images show single modality (a) morphological MR and (b) highly sensitive PET images of the lower limb of a mouse in which arthritis was induced by administration of the K/BxN mouse serum. The glucose analogue, fluorodeoxyglucose $\left({ }^{18} \mathrm{~F}-\mathrm{FDG}\right)$, used for PET imaging exhibits increased uptake kinetics in high-glucose-using cells of inflamed tissue. The PET/MR fusion image (c) shows the anatomic regions of higher glucose uptake, i.e. the joints due to inflammation and the liver due to physiologically high metabolism. NanoScan PET/MRI (Mediso, Budapest, Hungary). See Botz B, Bölcskei K, Kereskai L, et al. Differential regulatory role of pituitary adenylate cyclase-activating polypeptide in the serum-transfer arthritis model.

Arthritis Rheumatol 2014; 66: 2739-2750.

any organic molecule without changing its chemical properties. However, the very short half-life (minutes) of these radiopharmaceuticals necessitates in situ radioisotope production and compound labelling, which limits their availability to dedicated facilities equipped with cyclotrons. The somewhat longer half-life (110 minutes) of ${ }^{18} \mathrm{~F}$ already allows external production and transportation. ${ }^{39}$ Recently, other isotopes with longer half-life (13h to a few days), such as ${ }^{60,61,64} \mathrm{Cu},{ }^{76} \mathrm{Br}$, ${ }^{94} \mathrm{Tc},{ }^{89} \mathrm{Zr}$, or ${ }^{124} \mathrm{I}$, are gaining increasing attention and are also applied to clinical diagnosis or therapy followup studies. ${ }^{23}$ These radionuclides offer the advantages of relatively easy production and transportation, as well as the potential to transfer SPECT radiochemistry to PET, thus taking advantage of a number of already evaluated SPECT tracers. ${ }^{66}$ Micro-PET is one of the most frequently used preclinical imaging modalities, and plays an important role in oncological research (by tracking metabolism, gene expression, cell proliferation, angiogenesis, hypoxia or apoptosis ${ }^{73-76}$ ), cardiology (heart function and localizing cardiac infarction ${ }^{77}$ ), neurology (measuring cerebral metabolism and perfusion ${ }^{78,79}$ ), as well as drug development ${ }^{29,65,80}$ (Figure 2).

Micro-SPECT and micro-PET. The greatest advantage of PET, besides the somewhat higher sensitivity, is provided by the possibility of constructing physiological biomarkers labelled with positron emitting isotopes ${ }^{11} \mathrm{C},{ }^{13} \mathrm{~N},{ }^{15} \mathrm{O}$, or ${ }^{18} \mathrm{~F}$, with which physiological and pathological processes can be monitored virtually without interference. ${ }^{13,40}$ However, the physical properties of beta radiation (positron range, photon non-collinearity and random events) limit the achievable spatial resolution $(1-2.2 \mathrm{~mm}){ }^{68,81}$ The spatial resolution of modern micro-SPECT devices, by contrast, ranges between $0.35 \mathrm{~mm}$ and $0.7 \mathrm{~mm} .54,55$ The isotopes used for SPECT imaging have a longer half-life, are chemically stable and emit photons with specific energies determined by the isotope in use. Therefore, radiopharmaceuticals are easily transportable if they are not synthesized on site; also longer periods of data acquisition and the use of multiple tracers are possible. Meanwhile in the case of PET, tracer differentiation is not plausible due to the fixed photon energy of annihilation. ${ }^{23}$

Due to the effects of partial volume and spill-over of signals, achieving the desired quantifiable image contrast with an appropriate resolution for small-animal imaging usually requires a 20 -fold higher tracer concentration per gram of tissue than with human applications. ${ }^{82}$ However, the amount of chemical probe compound applicable per body mass is limited; excessive amounts of probe molecules might interfere with the physiological dynamic state of body constituents (e.g. by occupying more than $5 \%$ of the total receptor 
sites) and threatening the validity of the tracer principle. ${ }^{83}$ Furthermore, the maximal injected volume should not exceed $10 \%$ of the total blood volume in order to obviate adverse effects on circulation (in the case of laboratory mice, intravenous injections should not exceed $200 \mu \mathrm{L}) .{ }^{84}$ Both micro-PET and microSPECT provide unique functional information on a molecular level. However, this information is sometimes difficult to interpret because the images lack correlation with anatomical structures. The absence of detailed anatomical information can be readily eliminated by combining imaging modalities via a hybrid or fusion imaging (such as PET/MR, PET/CT, SPECT/CT and SPECT/MR). ${ }^{66}$ An especially interesting hybrid recently being introduced into the market is the micro-SPECT/MRI system. With this combination, the versatility and high chemical sensitivity of SPECT meets the superb soft tissue contrast and high resolution of MRI. This system brings novel possibilities of therapeutic research in nephrology, immunology, transplantation and oncology where studies with longer monitoring intervals in high resolution have long been sought. ${ }^{85,86}$

\section{Optical imaging}

Optical imaging in medicine utilizes special molecules which either act as a light source per se (luminescence) or can be excited externally to emit photons (fluorescence) and so enhance image contrast and monitor molecular processes. ${ }^{87}$ Bioluminescence occurs as luciferases (special enzymes synthesized by protists, fungi, insects or bacteria ${ }^{88}$ ) which catalyze the oxidation of luciferins (substrate), creating non-reactive oxyluciferins while releasing photons of light. ${ }^{89}$ In recent years, advances in genomics and genetic engineering have led to the isolation of different luciferase genes that can be transferred into single cells, cell cultures or entire organisms by way of DNA vectors. ${ }^{88}$ Following intraperitoneal or intravenous injection, luciferin is oxidized and the affected cells are lit up for $10-12 \mathrm{~min}$, which can then be detected by highly sensitive detectors. ${ }^{90}$ This method is very sensitive, even single cells can be detected, and is mainly used in oncological research.

The phenomenon of fluorescence differs from luminescence. Certain substances or molecules are capable of absorbing energy from an external light at a certain wavelength, while emitting photons with a typical (increased) shifted wavelength, which may be captured by charged-coupled detector (CCD) cameras. ${ }^{91}$ OI either utilizes fluorescent properties of endogenous substances (collagen or haemoglobin) or external fluorescent agents administered to the organism. These agents may be intravenous dyes (indocyanine green [ICG]), fluorescent-labelled antibodies, or artificially expressed molecules by genetically-modified cells (green fluorescent protein [GFP]). ${ }^{87,92}$

The main limitation of OI is the intraparenchymatous absorption and scattering of photons within a few millimetres, thereby strongly reducing penetration depth, and producing images which are not quantitative and have a suboptimal effective resolution. ${ }^{93}$ Light in the near infrared range penetrates tissue slightly better; nevertheless, this method is used predominantly in preclinical research (with a few exceptions, such as breast cancer imaging). ${ }^{94}$ By using multiple sourcedetector pairs reconstructed 3D images can be obtained (diffuse optical tomography [DOT]) with excellent sensitivity and good spatial resolution, which, in contrast to planar images, allows for accurate quantification and volumetric localization. ${ }^{95,96}$ The outstanding sensitivity renders OI a modality quite frequently utilized in smallanimal studies, especially in oncological research, in vivo stem-cell studies, or more recently, even to detect vascular endothelial growth factor (VEGF), integrin or matrix metalloprotease activity. ${ }^{97-99}$

The term OI also includes other techniques which utilize optical signals (besides luminescence or fluorescence). Laser speckle imaging, for example, is based on the acquisition (by CCD cameras) and analysis of interference patterns ('speckles') which appear when coherent light is scattered from a random medium. The movement of scattering particles such as erythrocytes causes phase shifts in the scattered light, changing the random interference pattern, which makes this method a powerful tool for perfusion imaging applications in tissues, such as the retina, skin and brain. Laser speckle imaging has become a standard tool in a variety of vascular diseases including dermatological complications, neurotrauma clinical therapy and preclinical research. ${ }^{100}$

A more recent technology combines the advantages of OI and US. Photoacoustic tomography (PAT) obtains images with high spatial resolution and improved contrast by detecting acoustic signals generated by pulsed laser light. ${ }^{101} \mathrm{~A}$ fraction of incident light pulse energy is absorbed by the target tissue causing thermal expansion, which propagates as a sound wave and can thus be detected by an acoustic detector, providing both structural and compositional information with depth penetration from over several millimetres to centimetres. ${ }^{102,103}$ PAT can be used for imaging oxygenation and perfusion at the microscopic level, ${ }^{104-106}$ molecular tissue composition, ${ }^{107,108}$ and is capable of highly-specific molecular and functional imaging with extrinsically administered optical or optoacoustic agents. ${ }^{109,110}$ As emerging concepts are translated into robust tools, this modality will fill important gaps in basic and translational research ${ }^{111,112}$ (Figure 3). 


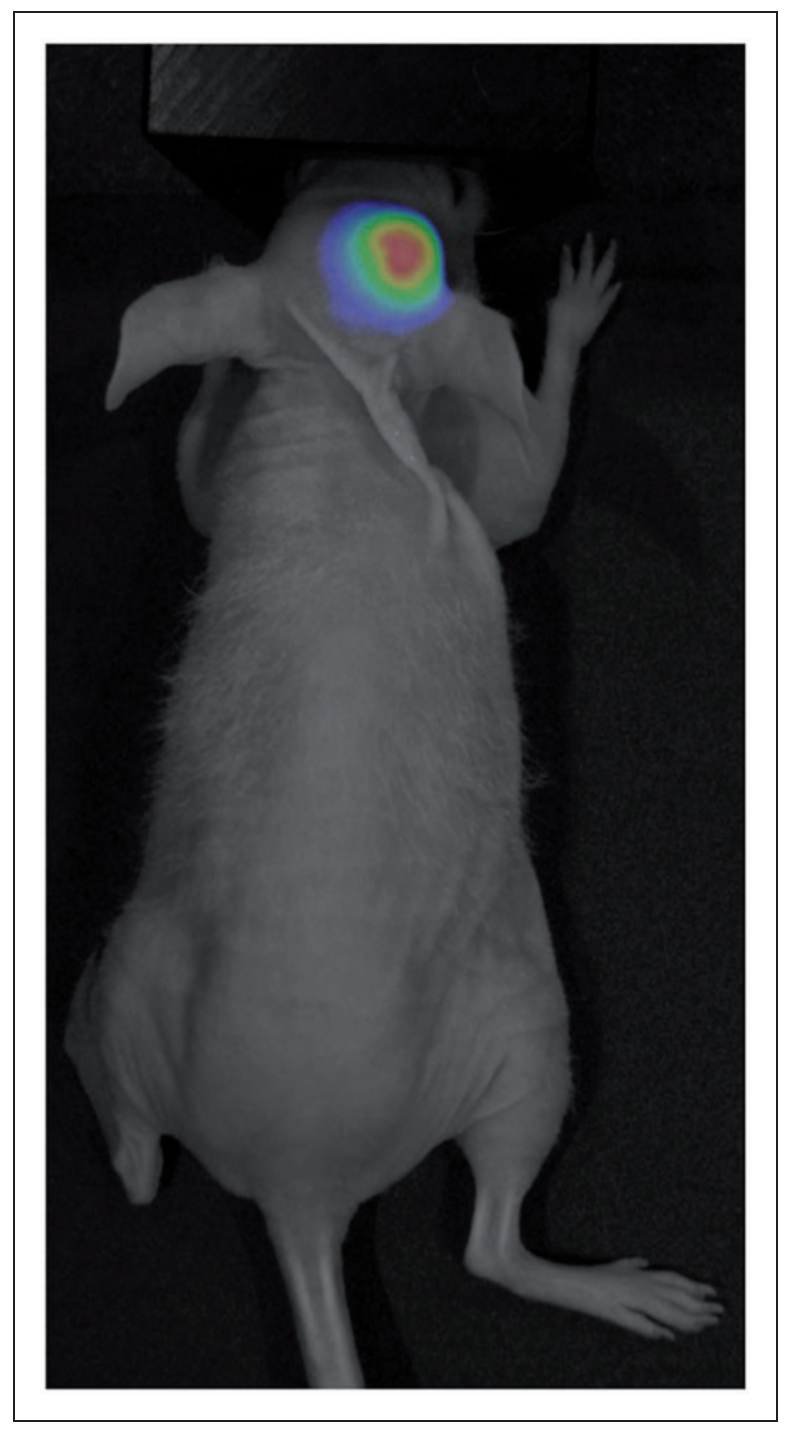

Figure 3. Fluorescent imaging of mCherry protein expression in U251 human glioma cells orthotopically injected to a mouse brain (strain: Crl:NU(NCr)-Foxn1nu/ nu). The newly formed tumour is well visualized as the image of fluorescence is superimposed on a grey-scale image of the mouse. FOBI fluorescent optical imaging system (NeoScience Co Ltd, Suwon, Korea). See Dico AL, Costa V, Martelli C, et al. MiR675-5p acts on HIF-1 $\alpha$ to sustain hypoxic responses: a new therapeutic strategy for glioma.

Theranostics 2016; 6: 1105-1118.

\section{Ultrasonography}

Ultrasonic imaging (echography, sonography, US) in small-animal studies is a fast and cost-efficient method, with high spatial and temporal resolutions, providing images with high sensitivity and contrast. ${ }^{113}$
US is based on the differing acoustic properties of tissue. Ultrasound waves, usually generated by piezoelectric crystals, are reflected on the border of adjacent tissue layers (with different acoustic impedance) creating an echo of sound wave, which can be detected and converted into electric signals by piezoelectric crystals. ${ }^{14,115}$ Preclinical ultrasound devices use much higher frequencies than commonly used ultrasound diagnostic systems $(20-50 \mathrm{MHz}$ versus $2-15 \mathrm{MHz})$. The higher the frequency, the higher the spatial resolution achieved, but at the expense of higher tissue attenuation, which results in a more superficial penetration. ${ }^{116,117}$ The introduction of dedicated US contrast agents further enhances image contrast and enables the analysis of biological and functional processes on a molecular level. ${ }^{118}$ Ultrasound biomicroscopy is able to produce real-time images with microscopic spatial resolutions $(30-60 \mu \mathrm{m})$ at ultrahigh frequencies (60-100 MHz). High-resolution ultrasound biomicroscopy is able to portray the beating heart of in utero embryonic mice, and is frequently used in cancer research or during the detection of human conjunctival melanomas. ${ }^{119,120}$ Ultrasound imaging has several extremely advantageous features: high spatial and temporal resolutions, real-time and functional imaging without ionizing radiation, broad availability and cost efficiency. However, to achieve images of high quality and reproducibility requires the expertise of a welltrained sonographer. ${ }^{115}$ However, US is incapable of imaging bone and gas-filled structures; and therefore it cannot be used routinely in brain, spinal cord or lung imaging. ${ }^{121}$

\section{Conclusions}

Preclinical imaging offers prodigious advantages over conventional ex vivo techniques, such as real-time monitoring, due to its non-destructive and non-invasive nature, and the possibility of simultaneously acquiring molecular, functional and anatomical information. Each individual imaging modality has its intrinsic advantages and disadvantages, yielding different kinds of information, which are most often complementary. The combination of high-resolution modalities (micro-MRI, micro- or nano-CT) and techniques bearing highly sensitive functional information (micro-PET or micro-SPECT) has become a major cornerstone in preclinical research and modern drug development.

\section{Acknowledgements}

Luisa Ottobrini (University of Milan, Italy) and Anna Maria Rapisarda (National Institutes of Health, USA) are gratefully acknowledged for the U251-mCherry cell line. 


\section{Declaration of conflicting interests}

The author(s) declared no potential conflicts of interest with respect to the research, authorship, and/or publication of this article.

\section{Funding}

The author(s) disclosed receipt of the following financial support for the research, authorship, and/or publication of this article: A Szijártó and K Szigeti were supported by the 'Janos Bolyai Research Fellowship Program' of the Hungarian Academy of Sciences. This study was funded by the Hungarian Research Grants OTKA-115607 and by the National Research, Development and Innovation Office NKFIH, grant No. K115607. The research leading to these results has received funding from the European Union Seventh Framework Programme FP7/2007-2013 under grant agreement No. 305311 (INSERT) and HEALTH-F22011-278850 (INMiND).

\section{References}

1. Zanzonico P. Noninvasive imaging for supporting basic research. In: Kiessling $\mathrm{F}$ and Pichler BJ (eds) Small Animal Imaging. Berlin: Springer, 2011, pp.3-16.

2. Weissleder $\mathrm{R}$ and Mahmood U. Molecular Imaging. Radiology 2001; 219: 316-333.

3. Massoud TF and Gambhir SS. Molecular imaging in living subjects: seeing fundamental biological processes in a new light. Genes Dev 2003; 17: 545-580.

4. Grassi R, Lagalla R and Rotondo A. Genomics, proteomics, MEMS and SAIF: which role for diagnostic imaging? Radiol Med 2008; 113: 775-778.

5. Alberti C. From molecular imaging in preclinical/clinical oncology to theranostic applications in targeted tumor therapy. Eur Rev Med Pharmacol Sci 2012; 16: 1925-1933.

6. Jiang Y, Zhao J, White D and Genant H. Micro CT and micro MR imaging of 3D architecture of animal skeleton. J Musculoskelet Neuronal Interact 2000; 1: 45-51.

7. Paulus MJ, Gleason SS, Easterly ME and Foltz CJ. A review of high-resolution X-ray computed tomography and other imaging modalities for small animal research. Lab Anim 2001; 30: 36-45.

8. Paulus MJ, Gleason SS, Kennel SJ, Hunsicker PR and Johnson DK. High resolution X-ray computed tomography: an emerging tool for small animal cancer research. Neoplasia 2000; 2: 62-70.

9. Badea C, Drangova M, Holdsworth D and Johnson G. In vivo small-animal imaging using micro-CT and digital subtraction angiography. Phys Med Biol 2008; 53: R319.

10. Beer AJ and Schwaiger M. Imaging of integrin $\alpha v \beta 3$ expression. Cancer Metastasis Rev 2008; 27: 631-644.

11. Ritman EL. Current status of developments and applications of micro-CT. Annu Rev Biomed Eng 2011; 13: 531-552.

12. Jelicks LA, Lisanti MP, Machado FS, Weiss LM, Tanowitz HB and Desruisseaux MS. Imaging of smallanimal models of infectious diseases. Am J Pathol 2013; 182: 296-304.
13. de Kemp RA, Epstein FH, Catana C, Tsui BM and Ritman EL. Small-animal molecular imaging methods. J Nucl Med 2010; 51: 18S-32S.

14. Cavanaugh D, Johnson E, Price RE, Kurie J, Travis EL and Cody DD. In vivo respiratory-gated micro-CT imaging in small-animal oncology models. Mol Imaging 2004; 3: 55-62.

15. Vogel J. Measurement of cardiac output in small laboratory animals using recordings of blood conductivity. Am J Physiol 1997; 273: H2520-H2527.

16. Kiessling F, Greschus S, Lichy MP, et al. Volumetric computed tomography (VCT): a new technology for noninvasive, high-resolution monitoring of tumor angiogenesis. Nat Med 2004; 10: 1133-1138.

17. Schambach SJ, Bag S, Schilling L, Groden C and Brockmann MA. Application of micro-CT in small animal imaging. Methods 2010; 50: 2-13.

18. Montet X, Rajopadhye M and Weissleder R. An albumin-activated far-red fluorochrome for in vivo imaging. ChemMedChem 2006; 1: 66-69.

19. Montet X, Pastor CM, Vallée J-P, et al. Improved visualization of vessels and hepatic tumors by micro-computed tomography (CT) using iodinated liposomes. Invest Radiol 2007; 42: 652-658.

20. Ghaghada KB, Badea CT, Karumbaiah L, et al. Evaluation of tumor microenvironment in an animal model using a nanoparticle contrast agent in computed tomography imaging. Acad Radiol 2011; 18: 20-30.

21. Ashton JR, West JL and Badea CT. In vivo small animal micro-CT using nanoparticle contrast agents. Front Pharmacol 2015; 6: 256.

22. Suckow CE and Stout DB. MicroCT liver contrast agent enhancement over time, dose, and mouse strain. Mol Imaging Biol 2008; 10: 114-120.

23. Cunha L, Horvath I, Ferreira S, et al. Preclinical imaging: an essential ally in modern biosciences. Mol Diagn Ther 2014; 18: 153-173.

24. Boone JM, Velazquez O and Cherry SR. Small-animal X-ray dose from micro-CT. Mol Imaging 2004; 3 : 149-158.

25. Winter PM, Caruthers SD, Kassner A, et al. Molecular imaging of angiogenesis in nascent $\mathrm{Vx}-2$ rabbit tumors using a novel $\alpha v \beta 3$-targeted nanoparticle and 1.5 tesla magnetic resonance imaging. Cancer Res 2003; 63: 5838-5843.

26. Beckmann N, Kneuer R, Gremlich HU, KarmoutyQuintana H, Blé FX and Müller M. In vivo mouse imaging and spectroscopy in drug discovery. NMR Biomed 2007; 20: 154-185.

27. Brown RW, Cheng Y-CN, Haacke EM, Thompson MR and Venkatesan R. Magnetic resonance imaging: physical principles and sequence design. Hoboken: John Wiley \& Sons, 2014.

28. Tremoleda JL, Khalil M, Gompels LL, WylezinskaArridge M, Vincent T and Gsell W. Imaging technologies for preclinical models of bone and joint disorders. EJNMMI Res 2011; 1: 11.

29. Pomper MG and Lee JS. Small animal imaging in drug development. Curr Pharm Des 2005; 11: 3247-3272. 
30. Kannurpatti SS and Biswal BB. Detection and scaling of task-induced fMRI-BOLD response using resting state fluctuations. Neuroimage 2008; 40: 1567-1574.

31. O'Connor JP, Jackson A, Parker GJ and Jayson GC. DCE-MRI biomarkers in the clinical evaluation of antiangiogenic and vascular disrupting agents. $\mathrm{Br} J$ Cancer 2007; 96: 189-195.

32. Ribot EJ, Trotier AJ, Castets CR, et al. Free-breathing 3D diffusion MRI for high-resolution hepatic metastasis characterization in small animals. Clin Exp Metastasis 2016; 33: 167-178.

33. Gujar SK, Maheshwari S, Björkman-Burtscher I and Sundgren PC. Magnetic resonance spectroscopy. J Neuro-Ophthalmol 2005; 25: 217-226.

34. Richards TL. Multinuclear Magnetic Resonance Spectroscopic Imaging. Encyclopedia of Analytical Chemistry. John Wiley \& Sons, Ltd, 2006.

35. He Q, Xu RZ, Shkarin P, et al. Magnetic resonance spectroscopic imaging of tumor metabolic markers for cancer diagnosis, metabolic phenotyping, and characterization of tumor microenvironment. Dis Markers 2004; 19: 69-94.

36. Bolo NR, Hodé Y, Nédélec J-F, Lainé E, Wagner G and Macher J-P. Brain pharmacokinetics and tissue distribution in vivo of fluvoxamine and fluoxetine by fluorine magnetic resonance spectroscopy. Neuropsychopharmacology 2000; 23: 428-438.

37. Eichhorn TR, Takado Y, Salameh N, et al. Hyperpolarization without persistent radicals for in vivo real-time metabolic imaging. Proc Natl Acad Sci USA 2013; 110: 18064-18069.

38. Siddiqui S, Kadlecek S, Pourfathi M, et al. The use of hyperpolarized carbon-13 magnetic resonance for molecular imaging. Adv Drug Deliv Rev 2016.

39. Koba W, Kim K, Lipton ML, et al. Imaging devices for use in small animals. Sem Nucl Med 2011; 41: 151-165.

40. Tsui BM and Kraitchman DL. Recent advances in smallanimal cardiovascular imaging. J Nucl Med 2009; 50: 667-670.

41. Czernin J, Weber WA and Herschman HR. Molecular imaging in the development of cancer therapeutics. Annu Rev Med 2006; 57: 99-118.

42. Fülöp A, Szijártó A, Harsányi L, et al. Demonstration of metabolic and cellular effects of portal vein ligation using multi-modal PET/MRI measurements in healthy rat liver. PLoS One 2014; 9: e90760.

43. Logan J, Fowler JS, Volkow ND, et al. Graphical analysis of reversible radioligand binding from time-activity measurements applied to [N-11C-methyl]-(-)-cocaine PET studies in human subjects. J Cereb Blood Flow Metab 1990; 10: 740-747.

44. Gjedde A. Calculation of cerebral glucose phosphorylation from brain uptake of glucose analogs in vivo: a re-examination. Brain Res Rev 1982; 4: 237-274.

45. Patlak CS, Blasberg RG and Fenstermacher JD. Graphical evaluation of blood-to-brain transfer constants from multiple-time uptake data. J Cereb Blood Flow Metab 1983; 3: 1-7.

46. Wagner HN. Nuclear medicine: 100 years in the making. J Nucl Med 1996; 37: 18N-37N.
47. Anger H, Powell M, Van Dyke D, Schaer L, Fawwaz R and Yano Y. Recent applications of the scintillation camera. Strahlentherapie (Sonderb) 1967; 65: 70-93.

48. Khalil MM, Tremoleda JL, Bayomy TB and Gsell W. Molecular SPECT imaging: an overview. Int $J \mathrm{Mol}$ Imaging 2011; 2011: 796025.

49. Peremans K, Cornelissen B, Van Den Bossche B, Audenaert $\mathrm{K}$ and Van de Wiele C. A review of small animal imaging planar and pinhole SPECT $\gamma$ camera imaging. Vet Radiol Ultrasound 2005; 46: 162-170.

50. Jaszczak RJ and Coleman RE. Single photon emission computed tomography (SPECT). Principles and instrumentation. Invest Radiol 1985; 20: 897-910.

51. Rogers W and Ackermann R. SPECT instrumentation. Am J Physiol Imaging 1991; 7: 105-120.

52. Peterson TE and Shokouhi S. Advances in preclinical SPECT instrumentation. $J$ Nucl Med 2012; 53: 841-844.

53. Peterson TE and Furenlid LR. SPECT detectors: the Anger camera and beyond. Phys Med Biol 2011; 56: R145-R182.

54. Meikle SR, Kench P, Kassiou M and Banati RB. Small animal SPECT and its place in the matrix of molecular imaging technologies. Phys Med Biol 2005; 50: R45-R61.

55. Vastenhouw B and Beekman F. Submillimeter total-body murine imaging with U-SPECT-I. J Nucl Med 2007; 48: 487-893.

56. Franc BL, Acton PD, Mari $\mathrm{C}$ and Hasegawa $\mathrm{BH}$. Small-animal SPECT and SPECT/CT: important tools for preclinical investigation. J Nucl Med 2008; 49: 1651-1663.

57. Liu Z, Kastis GA, Stevenson GD, et al. Quantitative analysis of acute myocardial infarct in rat hearts with ischemia-reperfusion using a high-resolution stationary SPECT system. J Nucl Med 2002; 43: 933-939.

58. Meoli DF, Sadeghi MM, Krassilnikova S, et al. Noninvasive imaging of myocardial angiogenesis following experimental myocardial infarction. J Clin Invest 2004; 113: 1684-1691.

59. Rodriguez-Porcel M. In vivo imaging and monitoring of transplanted stem cells: clinical applications. Curr Cardiol Rep 2010; 12: 51-58.

60. Pomper MG, Hammond $\mathrm{H}, \mathrm{Yu} \mathrm{X}$, et al. Serial imaging of human embryonic stem-cell engraftment and teratoma formation in live mouse models. Cell Res 2009; 19: 370-379.

61. Hanahan D and Weinberg RA. The hallmarks of cancer. Cell 2000; 100: 57-70.

62. Ponsky L, Cherullo E, Starkey R, Nelson D, Neumann D and Zippe C. Evaluation of preoperative ProstaScint scans in the prediction of nodal disease. Prostate Cancer Prostatic Dis 2001; 5: 132-135.

63. Sharma S and Ebadi M. SPECT neuroimaging in translational research of CNS disorders. Neurochem Int 2008; 52: 352-362.

64. Kung M-P, Hou C, Zhuang Z-P, Cross AJ, Maier DL and Kung HF. Characterization of IMPY as a potential imaging agent for $\beta$-amyloid plaques in double transgenic PSAPP mice. Eur J Nucl Med Mol Imaging 2004; 31: 1136-1145. 
65. Rudin M. Noninvasive structural, functional, and molecular imaging in drug development. Curr Opin Chem Biol 2009; 13: 360-371.

66. Kagadis GC, Loudos G, Katsanos K, Langer SG and Nikiforidis GC. In vivo small animal imaging: current status and future prospects. Med Phys 2010; 37: 6421-6442.

67. Turkington TG. Introduction to PET instrumentation. J Nucl Med Technol 2001; 29: 4-11.

68. Lecomte R. Technology challenges in small animal PET imaging. Nucl Instrum Methods Phys Res A 2004; 527: 157-165.

69. Hutchins GD, Miller MA, Soon VC and Receveur T. Small animal PET imaging. ILAR J 2008; 49: 54-65.

70. Levin CS and Zaidi H. Current trends in preclinical PET system design. PET Clin 2007; 2: 125-160.

71. Pichler BJ, Wehrl HF, Kolb A and Judenhofer MS. Positron emission tomography/magnetic resonance imaging: the next generation of multimodality imaging? Sem Nucl Med 2008; 38: 199-208.

72. Herzog $\mathrm{H}$ and Lerche C. Advances in clinical PET/MRI instrumentation. PET Clin 2016; 11: 95-103.

73. Höglund J, Shirvan A, Antoni G, et al. 18F-ML-10, a PET tracer for apoptosis: first human study. $J \mathrm{Nucl}$ Med 2011; 52: 720-725.

74. Vavere AL and Lewis JS. Cu-ATSM: a radiopharmaceutical for the PET imaging of hypoxia. Dalton Trans 2007; 43: 4893-4902.

75. Niu $\mathrm{G}$ and Chen $\mathrm{X}$. PET imaging of angiogenesis. PET Clin 2009; 4: 17-38.

76. Blasberg R. PET imaging of gene expression. Eur $J$ Cancer 2002; 38: 2137-2146.

77. Lecomte R, Croteau E, Gauthier MÉ, et al. Cardiac PET imaging of blood flow, metabolism, and function in normal and infarcted rats. IEEE Trans Nucl Sci 2004; 51: 696-704.

78. Schulz D, Southekal S, Junnarkar SS, et al. Simultaneous assessment of rodent behavior and neurochemistry using a miniature positron emission tomograph. Nat Methods 2011; 8: 347-352.

79. Vaska P, Woody C, Schlyer D, et al. RatCAP: miniaturized head-mounted PET for conscious rodent brain imaging. IEEE Trans Nucl Sci 2004; 51: 2718-2722.

80. Piel M, Vernaleken I and Rösch F. Positron emission tomography in CNS drug discovery and drug monitoring. J Med Chem 2014; 57: 9232-9258.

81. Tai Y-C, Ruangma A, Rowland D, et al. Performance evaluation of the microPET focus: a third-generation microPET scanner dedicated to animal imaging. $J \mathrm{Nucl}$ Med 2005; 46: 455-463.

82. Chatziioannou AF. Instrumentation for molecular imaging in preclinical research: micro-PET and microSPECT. Proc Am Thorac Soc 2005; 2: 533-536.

83. Henriksen $G$ and Drzezga A. Imaging in neurology research II: PET imaging of CNS disorders. In: Kiessling F and Pichler BJ (eds) Small animal imaging. Berlin: Springer, 2011, pp.499-513.

84. Hume SP, Gunn RN and Jones T. Pharmacological constraints associated with positron emission tomographic scanning of small laboratory animals. Eur J Nucl Med 1998; 25: 173-176.

85. Goetz C, Breton E, Choquet P, Israel-Jost V and Constantinesco A. SPECT low-field MRI system for small-animal imaging. J Nucl Med 2008; 49: 88-93.

86. Hutton BF, Occhipinti M, Kuehne A, et al. Development of clinical simultaneous SPECT/MRI. $\mathrm{Br}$ J Radiol 2016; 20160690.

87. Bremer C, Ntziachristos V and Weissleder R. Optical-based molecular imaging: contrast agents and potential medical applications. Eur Radiol 2003; 13: 231-243.

88. Wilson T and Hastings JW. Bioluminescence. Annu Rev Cell Dev Biol 1998; 14: 197-230.

89. Greer LF and Szalay AA. Imaging of light emission from the expression of luciferases in living cells and organisms: a review. Luminescence 2002; 17: 43-74.

90. Sadikot RT and Blackwell TS. Bioluminescence imaging. Proc Am Thorac Soc 2005; 2: 537-540.

91. Kraayenhof R, Visser AJ and Gerritsen H. Fluorescence spectroscopy, imaging and probes: new tools in chemical, physical and life sciences. Berlin: Springer Science \& Business Media, 2012.

92. Weissleder R. Scaling down imaging: molecular mapping of cancer in mice. Nat Rev Cancer 2002; 2: 11-18.

93. James ML and Gambhir SS. A molecular imaging primer: modalities, imaging agents, and applications. Physiol Rev 2012; 92: 897-965.

94. Schulz RB and Semmler W. Fundamentals of optical imaging. In: Molecular Imaging I. Berlin: Springer, 2008, pp.3-22.

95. Culver J, Akers W and Achilefu S. Multimodality molecular imaging with combined optical and SPECT/ PET modalities. J Nucl Med 2008; 49: 169-172.

96. Ntziachristos V, Bremer $\mathrm{C}$ and Weissleder R. Fluorescence imaging with near-infrared light: new technological advances that enable in vivo molecular imaging. Eur Radiol 2003; 13: 195-208.

97. Ray P, Wu AM and Gambhir SS. Optical bioluminescence and positron emission tomography imaging of a novel fusion reporter gene in tumor xenografts of living mice. Cancer Res 2003; 63: 1160-1165.

98. Snoeks T, Löwik C and Kaijzel E. 'In vivo' optical approaches to angiogenesis imaging. Angiogenesis 2010; 13: 135-147.

99. Boddington S, Henning TD, Sutton EJ and DaldrupLink HE. Labeling stem cells with fluorescent dyes for non-invasive detection with optical imaging. $J$ Vis Exp 2008; (14): e686.

100. Boas DA and Dunn AK. Laser speckle contrast imaging in biomedical optics. J Biomed Opt 2010; 15: 011109.

101. Kruger RA. Photoacoustic ultrasound. Med Phys 1994; 21: 127-131.

102. Wang LV and $\mathrm{Hu} \mathrm{S}$. Photoacoustic tomography: in vivo imaging from organelles to organs. Science 2012; 335: 1458-1462.

103. Xu M and Wang LV. Photoacoustic imaging in biomedicine. Rev Sci Instrum 2006; 77: 041101. 
104. Maslov K, Zhang HF, Hu S and Wang LV. Opticalresolution photoacoustic microscopy for in vivo imaging of single capillaries. Opt Lett 2008; 33: 929-931.

105. Smith L, Varagic J and Yamaleyeva L. Photoacoustic imaging for the detection of hypoxia in the rat femoral artery and skeletal muscle microcirculation. Shock 2016; 46: $527-530$.

106. Gamelin J, Maurudis A, Aguirre A, et al. A real-time photoacoustic tomography system for small animals. Opt Express 2009; 17: 10489-10498.

107. Beard P. Biomedical photoacoustic imaging. Interface Focus 2011; rsfs20110028.

108. Wang B, Su JL, Amirian J, Litovsky SH, Smalling R and Emelianov S. Detection of lipid in atherosclerotic vessels using ultrasound-guided spectroscopic intravascular photoacoustic imaging. Opt Express 2010; 18: 4889-4897.

109. Zhang HF, Maslov K, Stoica G and Wang LV. Functional photoacoustic microscopy for high-resolution and noninvasive in vivo imaging. Nat Biotechnol 2006; 24: 848-851.

110. Bednar B and Ntziachristos V. Opto-acoustic imaging of drug discovery biomarkers. Curr Pharm Biotechnol 2012; 13: 2117-2127.

111. Hu S. Emerging concepts in functional and molecular photoacoustic imaging. Curr Opin Chem Biol 2016; 33: 25-31.

112. Liu Y, Nie L and Chen X. Photoacoustic molecular imaging: from multiscale biomedical applications towards early-stage theranostics. Trends Biotechnol 2016; 34: 420-433.

113. Voigt J-U. Ultrasound molecular imaging. Methods 2009; 48: 92-97.

114. Liang $\mathrm{H}$ and Blomley $\mathrm{M}$. The role of ultrasound in molecular imaging. $\mathrm{Br} J$ Radiol 2003; 76: 140-150.

115. Cootney RW. Ultrasound imaging: principles and applications in rodent research. ILAR $J$ 2001; 42: 233-247.

116. Hynynen K, Freund WR, Cline HE, et al. A clinical, noninvasive, MR imaging-monitored ultrasound surgery method. Radiographics 1996; 16: 185-195.

117. Cline HE, Schenck JF, Hynynen K, Watkins RD, Souza SP and Jolesz FA. MR-guided focused ultrasound surgery. J Comput Assist Tomogr 1992; 16: 956-965.

118. Deshpande N, Needles A and Willmann JK. Molecular ultrasound imaging: current status and future directions. Clin Radiol 2010; 65: 567-581.

119. Ho VH, Prager TC, Diwan H, Prieto V and Esmaeli B. Ultrasound biomicroscopy for estimation of tumor thickness for conjunctival melanoma. $J$ Clin Ultrasound 2007; 35: 533-537.

120. Cheung AM, Brown AS, Hastie LA, et al. Three-dimensional ultrasound biomicroscopy for xenograft growth analysis. Ultrasound Med Biol 2005; 31: 865-870.

121. Greco A, Mancini M, Gargiulo S, et al. Ultrasound biomicroscopy in small animal research: applications in molecular and preclinical imaging. $J$ Biomed Biotechnol 2012; 2012: 519238.

\section{Résumé}

Depuis les dernières décennies, les dispositifs d'imagerie sont devenus des outils indispensables pour les sciences fondamentales, la recherche préclinique et le développement des médicaments modernes. Les technologies d'imagerie in vivo haute résolution à évolution rapide offrent une opportunité unique d'étudier les processus biologiques des organismes vivants en temps réel à l'échelle moléculaire. Les modalités d'imagerie de pointe pour les petits animaux fournissent des images non-invasives riches en informations quantitatives fonctionnelles et anatomiques, qui permettent des études longitudinales et une surveillance précise de la progression de la maladie et de la réponse au traitement dans des modèles de maladies différentes. Le nombre d'animaux utilisés dans une recherche scientifique peut ainsi être substantiellement réduit grâce aux techniques d'imagerie, ce qui est en parfaite conformité avec les initiatives éthiques de la politique des 3R (réduction, raffinement, remplacement) formulée par Russel et Burch ; la variabilité biologique peut en outre être atténuée, chaque animal étant utilisé comme son propre témoin. Les modalités d'imagerie les plus appropriées et les plus utilisées pour l'imagerie in vivo de petits animaux sont l'imagerie optique (IO), l'ultrasonographie (US), la tomographie par ordinateur (CT), l'imagerie à résonance magnétique (IRM) et enfin les procédés de médecine nucléaire: la tomographie par émission de positons (TEP) et la tomographie par émission monophotonique (TEMP).

\section{Abstract}

Bildgebende Geräte sind in den vergangenen Jahrzehnten zu unverzichtbaren Instrumenten für Basiswissenschaften, präklinische Forschung und moderne Arzneimittelentwicklung geworden. Die sich rasch entwickelnden hochauflösenden In-vivo-Bildgebungstechniken bieten eine einmalige Gelegenheit zum Studium biologischer Prozesse lebender Organismen in Echtzeit auf Molekularebene. Modernste bildgebende Verfahren für Kleintiere liefern nicht-invasiv erzeugte Bilder mit einer Fülle quantitativer 
anatomischer und funktioneller Informationen, die Längsschnittuntersuchungen zur präzisen Überwachung von Krankheitsverläufen und Ansprechen auf Therapien bei verschiedensten Krankheitsmodellen ermöglichen. Die Anzahl der zu wissenschaftlichen Zwecken verwendeten Tiere kann beim Einsatz bildgebender Verfahren wesentlich gesenkt werden, was voll und ganz mit dem ethischen Anspruch des von Russel und Burch formulierten 3R-Prinzips (Reduzieren, Verbessern, Vermeiden) konform ist. Zudem kann die biologische Variabilität gemindert werden, da jedes Tier seine eigene Kontrolle ist. Die für In-vivo-Bildgebung bei Kleintieren geeignetsten und am häufigsten eingesetzten Bildgebungsverfahren sind optische Bildgebung (OI), Ultraschall (US), Computertomografie (CT), Kernspintomografie (MRI) sowie die Methoden der Nuklearmedizin: Positronen-Emissions-Tomografie (PET) und Einzelphotonen-Emissionscomputertomografie (SPECT).

\section{Resumen}

En décadas recientes, los dispositivos para obtener imágenes se han convertido en herramientas indispensables en las ciencias básicas, la investigación preclínica y en el desarrollo de los fármacos modernos. Las tecnologías de imagen in vivo de alta resolución y con un rápido avance ofrecen una oportunidad única para estudiar procesos biológicos de organismos vivos en tiempo real a nivel molecular. Las innovadoras modalidades de imágenes para animales pequeños ofrecen imágenes no invasivas ricas en información funcional y anatómica cuantitativa, lo cual hace que puedan realizarse estudios longitudinales permitiendo un control preciso del avance de enfermedades y de la respuesta a terapias en modelos de distintas enfermedades. El número de animales en una investigación científica puede reducirse sustancialmente utilizando técnicas de imagen, lo cual cumple totalmente con los esfuerzos éticos de la política de las $3 \mathrm{R}$ (reducción, refinamiento, reemplazol formuladas por Russell y Burch; y además, la variabilidad biológica puede ser mitigada, ya que cada animal sirve como su propio control. Las modalidades de imagen más adecuadas y utilizadas habitualmente para conseguir imágenes in vivo de animales pequepos son la imagen óptica (OI), ultrasonografía (US), tomografía computerizada (CT), imagen de resonancia magnética (MRI) y finalmente los métodos de medicina nuclear: tomografía por emisión de positrones (PET) y tomografía computerizada por emisión de fotón único (SPECT). 